\title{
INSTRUCTIONAL LEADERSHIP IN SUB-SAHARAN AFRICA: POLICY AND PRACTICE
}

\author{
Abstract \\ Design/methodology/approach
}

This paper reports the findings of a systematic literature review, and participant interviews, in six subSahara African countries. The research links to the British Council's initiative to develop instructional leadership in developing contexts, including the six countries featured in this submission.

Purpose

The purpose of the paper is to report the findings of a synthesis of literature reviews and stakeholder interviews conducted in Nigeria, Sierra Leone, Sudan, Tanzania, Zambia, and Zimbabwe. The synthesis provides an overview of instructional leadership policy and practice in these six countries.

\section{Findings}

The findings show diverse policy and practice of instructional leadership in these African contexts. Three have no explicit policies on this important leadership construct while the others have relevant policy statements but limited evidence of instructional leadership practice.

\section{Research limitations/implications}

The research provides an overview of instructional leadership policy and practice in these six countries, but more school-based research is required to develop grounded evidence on whether and how this is practiced. The pandemic inhibited such school-based research in 2020 . The study provides emerging evidence of the impact of instructional leadership on school and student outcomes, confirming what is known from international research.

\section{Practical implications}

Developing awareness of how instructional leadership can improve student learning, linked to appropriate training, could lead to more effective schools.

\section{Social implications}

The Sustainable Development Goals stress the importance of high quality education for economic and social development. Leadership is an important aspect of quality and the research reported in this paper shows the potential for instructional leadership to enhance student learning.

\section{Originality/value}

This is the first cross-national study of instructional leadership in sub-Saharan Africa. 


\section{Introduction}

There is growing evidence that high quality leadership is essential for student growth and school improvement, accounting for up to 27 per cent of variation in student outcomes (Leithwood et al 2006). Bush (2020) discusses several leadership models, noting that transformational, distributed, and instructional approaches are particularly prominent in the leadership literature. Malaysia is one country which advocates these three models, to support its educational reform agenda (Ministry of Education, 2013).

Robinson et al's (2008) meta-analysis of published research indicates that instructional leadership has more powerful effects on student outcomes than other leadership models. The closer leaders are to the core business of teaching and learning, the more likely they are to make a difference to students (ibid). Shatzer et al's (2014) study of elementary schools in the US reached a similar conclusion that instructional leadership accounted for more of the variance in student outcomes than transformational leadership.

Bush and Glover (2014: 556) stress that 'instructional leadership, or leadership for learning, focuses primarily on the direction and purpose of leaders' influence; targeted at student learning via teachers'. The Malaysia Education Blueprint (2013: E27) claims that 'an outstanding principal is one focused on instructional and not administrative leadership'. Hallinger and Lee (2014: 6) note that 'instructional leadership from the principal is essential for the improvement of teaching and learning in schools'. However, they add that in many parts of the world, the practice of instructional leadership remains both poorly understood and outside the main job description of the principal' (ibid).

The British Council's Connecting Classrooms through Global Learning (CCGL) programme is promoting and developing instructional leadership because, as discussed above, this can have a positive impact on improving the quality of teaching and lead to enhanced student outcomes. CCGL aims to build the capacity of school leaders, with a specific focus on improving instructional leadership in schools. Linked to this initiative, the British Council ${ }^{1}$ commissioned research, and systematic literature reviews, in six sub-Saharan countries, Nigeria, Sierra Leone, Sudan, Tanzania, Zambia, and Zimbabwe. This links to the UN's Sustainable Development Goals, especially SDG 4 relating to quality education. This focus on instructional leadership is supported by compelling evidence that, where leaders focus on the quality of classroom learning, student outcomes improve. The six country reports informed the development of a report to the British Council (author, 2020), which underpins this paper.

\footnotetext{
${ }^{1}$ The ideas discussed in the paper are those of the authors, not the British Council
} 


\section{Literature Review}

\section{Instructional leadership and school improvement}

The international research on school improvement shows that the two main factors influencing the quality of education are classroom practice and leadership. Leithwood et al (2006) explain that principals can impact on classroom teaching by adopting a proactive approach and becoming 'instructional' leaders. Robinson's (2007:21) meta-analysis of the research on the effects of leadership shows that the impact on student outcomes is likely to be greater where there is direct leader involvement in the oversight of, and participation in, curriculum planning and co-ordination, teacher learning and professional development. 'The closer leaders are to the core business of teaching and learning, the more likely they are to make a difference to students' (Ibid).

\section{Defining instructional Leadership}

Bush (2011) includes instructional leadership as one of nine leadership models. He comments that this model is very important because it targets the school's central activities, teaching and learning. It differs from other leadership approaches because it focuses on the direction of influence, rather than its nature and source. Southworth (2002: 79) says that 'instructional leadership . . is strongly concerned with teaching and learning, including the professional learning of teachers as well as student growth'. Bush and Glover (2003: 10) add that:

"Instructional leadership focuses on teaching and learning and on the behaviour of teachers in working with students. Leaders' influence is targeted at student learning via teachers. The emphasis is on the direction and impact of influence rather than the influence process itself".

\section{Dimensions of effective instructional leadership}

The international literature and research offer guidance on the dimensions of effective instructional leadership. The English NCSL (2005: 38) says that 'improving the quality of learning and teaching is the most important thing that school leaders do'. Hallinger and Heck (1999) argue that instructional leaders influence learning and teaching in three ways:

\section{Directly, by personal intervention}

This may be enacted through their own teaching, or through modelling good practice. 


\section{Reciprocally, by their work alongside other teachers}

This may be enacted through classroom observation and constructive feedback.

\section{Indirectly, via other staff}

This may be enacted, for example, through dialogue with teachers.

Monitoring, followed by constructive feedback, and modelling good practice, are the instructional leadership strategies most frequently reported in the literature.

\section{Monitoring}

Southworth (2004) says that monitoring includes analysing and acting on students' progress and outcome data, for example assessment and test scores. 'Leadership is stronger when it is informed by data on students' learning, progress and achievements as well as by direct knowledge of teaching practices and classroom dynamics' (p.79). He adds that monitoring involves visiting classrooms, observing teachers at work and providing them with feedback. The English Office for Standards in Education (Ofsted 2003) found that there was a very strong link between good monitoring and good teaching. Southworth (ibid: 80) adds that 'monitoring classrooms is now an accepted part of leadership'. He concludes that monitoring is a widely distributed role, including head teachers, deputies and heads of department. Effective monitoring requires classroom observation.

\section{Observation}

O'Sullivan (2006: 253) stresses that educational quality can only be improved if there is systematic observation of what is happening in the classroom. This involves recording, analysing and reflecting on inter-relationships, interactions and outcomes and is critical to assessing and improving quality. She states that lesson observation can answer the 'what', 'how' and 'why' questions:

- 'What is the current state of educational quality in schools?'

- 'How can it be realistically improved with the available resources?'

- 'Why is the quality of education poor?'

Observation needs to be seen as a formative process, intended to raise standards of classroom practice, if it is to gain the co-operation of educators. It should also regarded as a 'normal' aspect of school management if it is to become embedded. This is likely to require a paradigm shift in many schools, prompted by firm but supportive leadership (Bush 2013). 
Where educators' pedagogic skills are weak, monitoring alone is unlikely to be effective in raising standards. Identifying aspects needing improvement is only a starting point. Good feedback is essential but this may need to be supported by professional development. While workshops may help to improve classroom teaching, modelling of good practice by the principal, the HoD or another educator, is more likely to be produce favourable outcomes. Southworth (2004: 78) claims that 'modelling is all about the power of example'. Successful leaders are aware that they must set an example and use their actions to show how colleagues should behave.

\section{Critiques of instructional leadership}

Despite its prominence, instructional leadership has been criticized on two grounds. First, it is perceived to be primarily concerned with teaching rather than learning (Bush 2013). The second criticism is that it 'focused too much on the principal as the centre of expertise, power and authority' (Hallinger 2003: 330). As a consequence, it tends to ignore or underplay the role of other leaders such as deputy principals, middle managers, leadership teams, and classroom teachers. Lambert (2002: 37) claims that 'the days of the lone instructional leader are over. We no longer believe that one administrator can serve as the instructional leader for the entire school without the substantial participation of other educators'. This argument is underpinning by two related considerations. First, principals lack the time to be the only instructional leaders, particularly in larger schools. This is partly because of administrative demands, as we discuss below, and partly because it would be impossible to visit all classrooms on a regular basis. Second, principals may lack the specific expertise to assess the quality of teaching and learning in terms of subject knowledge.

Despite these critiques, policy-makers continue to stress the importance of instructional leadership as a vehicle for school improvement. This prompted the British Council to develop a programme of instructional leadership training for school leaders in six sub-Saharan countries, as noted above. The British Council commissioned the authors to carry out a literature review, and to conduct research, in these six countries.

\section{Conceptual Overview}

Hallinger (2019) argues that the conceptualisation of instructional leadership has matured since 2010. Research in this period includes evidence of several 'paths' connecting instructional leadership and student outcomes. These include several teacher-related aspects, notably teacher commitment, collective teacher efficacy, teacher trust, teacher 
capacity, and teacher engagement in professional learning. These studies collectively suggest that school principals achieve impact on student learning by shaping the school culture, designing work structures and motivating and influencing teachers (Hallinger, 2019). Leithwood et al. (2010) added a fourth path which they refer to as the 'Family Path. This recognizes the important continuing influence that parents have on their children's learning, and highlights leadership practices that can leverage positive parental interest and involvement during their schooling years. Hallinger and Heck (1996) proposed that leadership effects on student learning could also be conceptualized as a 'reciprocal process' of mutual influence between the principal and other stakeholders. Robinson (2007) identified teacher professional learning as a particularly 'high value path' through which principals can contribute to student learning. Hallinger (2019) concludes that instructional leadership remains highly relevant as one of the core roles of school leaders.

\section{Methods}

The purpose of the study was to generate evidence about how school leaders spend their time, and how much time they have available for instructional tasks, the nature of existing structures and roles in schools, and the challenges and opportunities for effective instructional leadership.

These aims lead to five specific research questions identified by the British Council and addressed by the researchers:

1. Who are regarded as school leaders and what do they do, linked to leadership structures and roles in schools, and who is responsible for instructional leadership?

2. How do school leaders spend their time, including the balance of administrative and instructional tasks?

3. What do policies say about instructional leadership and who is responsible for it at school level?

4. What other leadership roles exist in schools that could possibly take on some of administrative responsibilities of school leaders?

5. What is the culture of delegation in schools?

Six in-country researchers first carried out desk research to identify and review literature related to instructional leadership. They then conducted interviews with various stakeholders, including ministry officials and school principals.

Sampling 
Data collection was carried out from March 2020, just as schools were closing due to the impact of the COVID-19 pandemic. As a consequence, the in-country researchers adopted opportunity sampling, interviewing school and system leaders, and other stakeholders. We acknowledge that this mode of sampling has limitations, but it did provide helpful, and wide-ranging, perspectives on instructional leadership from 55 participants across the six countries. Table 1 shows a summary of participants.

\begin{tabular}{|c|c|c|c|c|c|c|c|}
\hline Stakeholder & Nigeria & $\begin{array}{l}\text { Sierra } \\
\text { Leone }\end{array}$ & Sudan & Tanzania & Zambia & Zimbabwe & Total \\
\hline Principals & 4 & 1 & 10 & 10 & 1 & 1 & 27 \\
\hline Vice-principals & 2 & 1 & & & 1 & 1 & 5 \\
\hline $\begin{array}{l}\text { Ministry of Education } \\
\text { staff }\end{array}$ & 2 & 2 & 4 & 3 & 2 & & 13 \\
\hline School board chair & & & & & 1 & & 1 \\
\hline Private bodies & 2 & & & & 1 & & 3 \\
\hline Teacher union officials & & 1 & & & & 2 & 3 \\
\hline Lecturers & & & & & & 1 & 1 \\
\hline NGOs & 1 & & & 1 & & & 2 \\
\hline Total & 11 & 5 & 14 & 14 & 6 & 5 & 55 \\
\hline
\end{tabular}

Table 1: stakeholder interviews

\section{Data collection and analysis}

As noted above, opportunity sampling was used to identify 'information-rich' participants, with knowledge about the policy and practice of instructional leadership. These were interviewed in person, or online, depending on the availability and preferences of participants, and the impact of the pandemic. Each in-country researcher also carried out a review of the academic and 'grey' literature on instructional leadership in the countries for which they had responsibility. The grey literature mainly comprised online sources on the policy and practice of educational leadership.

Data analysis involved two stages. First, the in-country researchers provided a report structured by themes linked to the research questions. The interviews were coded by theme and sub-theme. The lead author then produced an overall synthesis of the data. This synthesis provided a starting point for this article. Validity was enhanced through two main processes. First, the interview data were triangulated through a systematic review of academic and grey literature. Second, a significant number of interviews were conducted, 55 in total, leading to data saturation and confirmation. 
However, a limitation of the research is the opportunity sampling, so the data are illustrative rather than generalisable.

\section{Findings and Discussion}

The findings are structured thematically, including themes linked to the research questions and those 'emergent' from the literature review and the interviews. These themes are:

- Understanding instructional leadership

- Policies on instructional leadership

- Roles and structures for instructional leadership

- Balancing instructional and administrative activities

- Delegation and distributed leadership

- Resourcing instructional leadership

The discussion below combines findings from all six countries linked to the wider literature on instructional leadership, so that findings can be linked to existing scholarship on this leadership model.

\section{$\underline{\text { Understanding instructional leadership }}$}

Hallinger (2019) claims that instructional leadership has matured as a global leadership construct, but this is much less evident in sub-Saharan Africa. There are no clear definitions of instructional leadership in the literature reviewed from Sudan, Tanzania, or Sierra Leone. The Sudanese literature indicates that principals lack understanding of their instructional role and that they devote most of their time and attention to administration (Alkalifa and Adil, 2015; Ahmed, 2015). The concept of instructional leadership is still very new in Sierra Leone and there is only fragmented information available on the subject. However, systems have been established by the government to support school leaders to set goals and execute tasks to enhance school development.

Although there is no official policy statement, several Zimbabwean researchers provide definitions of instructional leadership. According to Makamani (2015: 51), it has four key components; "visible presence of the school head, resource provision by the school head, the head as an instructional resource and lastly the head as a good communicator". Sibanda et al (2011: 21) identify five key components; "defining and communicating a clear mission, goals and objectives; managing curriculum and instruction; supervising teaching; monitoring learner progress; promoting instructional climate". 
The Nigerian Policy on Education encourages teachers to lead through the implementation of curriculum in classrooms, to facilitate the improvement of student learning. Principals are expected to drive instructional goals in the school, organise the learning environment, manage resources, and recruit, dismiss and train staff. In Zambia, Kabeta et al (2013: 1877) argue that the premise of instructional leadership is to lead teachers and students to reach their full potential by creating a conducive learning environment, defining and communicating shared goals, [and] monitoring the teaching and learning process'.

Instructional leadership, as a concept and a practice, remains a novel term in these six countries. It is weakly understood in these contexts and the definitions available in the literature are mainly derived from international settings rather than reflecting in-country practice. There is emerging recognition that school leaders have an important role to play in enhancing educational quality, although the language of instructional leadership is rarely used. Contextualised definitions are required that connect instructional leadership to wider school policies and practice in these specific settings.

\section{Policies on instructional leadership}

Sudan, Sierra Leone, and Zimbabwe have no explicit policies on instructional leadership, so this has to be inferred from more general policy statements. In Sudan, the term 'instructional leadership' is not used or known. Despite the many laws and regulations, little emphasis is put on the quality of teaching and learning and thus the quality of learning inside the classrooms remains low. All the laws and regulations contain the phrase 'Good Education' with little information about what this means or how it will be accomplished. In practice, the quality of learning is perceived to be poor (UNICEF 2020).

In Zimbabwe, there is no specific policy aimed at instructional leadership, making it difficult for school leaders who also lack formal training in instructional leadership (Musandu, 2018). There are no specific policies on instructional leadership in Sierra Leone but there is emerging recognition of its potential for improving the country's education system. One stakeholder, interviewed by the researcher, the district coordinator for Free Quality Education, argues that 'there is a clear need for research on instructional leadership in Sierra Leone to provide a reliable roadmap that would stimulate and strengthen the country's efforts to improve quality teaching and learning across all schools'.

Zambia, Tanzania, and Nigeria do have policy statements about instructional leadership but there is little evidence that such policies are being enacted effectively, or at all. Zambia has a dated National Policy on Education, Educating our Future (Ministry of Education 1996), that spells out instructional 
leadership by head teachers as a priority in enhancing the quality of teaching and learning. This 1996 policy document also asserts that schools 'have a clear focus on learning, with school time being productively used in a systematic approach to teaching and learning. The school's instructional tasks take precedence over all other activities' (Ibid: 154). Kabeta et al (2013) offer a more recent view, that there is a gap in the general comprehension of instructional leadership, and lack of clear guidelines on how to execute it.

The Tanzanian School Improvement Toolkit (MoEVT, URT 2013,) documents how leaders should lead the improvement of instruction. It provides guidelines on how school leaders should engage the school community, carry out continuous assessment of teachers, track teacher attendance, teacher motivation and accountability, enforce supervision and coaching of teachers, and how they should source teaching and learning materials. Nyambo (2017) also notes that the Tanzanian government authorizes school leaders as internal supervisors to ensure implementation of educational policy, regulations, programmes, directives, and monitoring instruction, to enhance learners' achievements. Nigeria's policy on education encourages instructional leadership with an emphasis on improving curriculum in schools to improve learning outcomes. This is achieved through NERDC, which is responsible for developing, reviewing, and enriching curriculum at all levels. The policy also encourages Instructional leadership through its emphasis on teacher education and evaluation.

The collective evidence from these six countries indicates limited policy foci on instructional leadership. Three of them have no explicit instructional leadership policies, instead having more general comments about educational quality. Even where such policies exist, they are often not enacted, as school-level awareness is limited. None of these countries has a fully developed instructional leadership model, encapsulating advice about monitoring, modelling, and mentoring, as suggested by Bush (2013). Arguably, school improvement would be enhanced if such a model is developed at the system level and implemented by school principals and other leaders.

\section{$\underline{\text { Roles and structures for instructional leadership }}$}

There is a distinction between external and internal roles for instructional leadership. Because of the dominance of the hierarchy, in all these countries, the external structures for instructional leadership, sometimes framed as instructional supervision, have a powerful influence on quality processes in schools. However, instructional leadership is generally understood to be an internal school function (Bush 2013, Hallinger 2019), and that is the focus of this article. 
Globally, schools almost always have a senior leader with the title of principal or head teacher, usually supported by other leaders, such as deputy or vice-principal, and middle leaders, such as heads of departments or subject leaders. This near-universal model also applies in the six sub-Saharan countries.

In Sudan, the head teacher is considered as the leader of the whole school, responsible for all administrative, and educational activities within the school. The school principal is supported by one or two deputies depending on the size of the school. Each subject within the school has a department head. Ayane and Chekol (2019) report that almost all instructional leaders are subject specialists who lack the skills, training, commitment, and motivation to accomplish their leadership tasks.

The Zambian National policy identifies the school head as an instructional leader. The secondary head teacher, interviewed for the research, comments that 'my role as an instructional leader is to ensure that I support my teachers and learners in the learning process by providing the required resources within my means. I monitor the teaching and learning through classroom observations. I also motivate my teachers'. The National Education Policy document, Educating our Future, directs that, 'before anything else, the school head should be an Instructional leader who enthuses teachers and learners' (Ministry of Education, 1996: 159). However, there is little guidance on what is expected of them. School heads are profiled as instructional leaders, but nothing is said about other senior and middle being instructional leaders.

In Tanzania, head teachers are recognized as internal instructional supervisors and their core function is to ensure that the curriculum is implemented according to the rules and regulations, through monitoring, the preparation and use of teaching professional documents such as syllabi, schemes of work, lesson plans, subject log books and lesson notes as well as classroom instruction provided by teachers to pupils (MoEVT, 2013, Manaseh, 2016). ). Nine of the 10 heads interviewed for this study concur that the government, school communities, staff and students consider them to be Instructional leaders.

Kaai (2016) indicates that Tanzanian school leaders communicate and drive instructional goals but also notes that the study participants were not able to explain the vision and mission of their schools. Nyambo (2017) adds that Tanzanian head teachers were not engaged in classroom observation, and that they were not aware that they are supposed to provide feedback to teachers after classroom observation. This study highlights a lack of knowledge and skills about instructional leadership amongst head teachers, who only marginally monitor teachers' performance and only partially take action to correct mistakes made by teachers. 
In Sierra Leone, there is no published research on instructional leadership, but a teacher union official offered comments about how it is interpreted in this context. 'At the school level, there are principals, head teachers, senior teachers who are also considered as instructional leaders as a result of their involvement in the development of the teaching and learning processes in their schools'.

The internal leadership structure in Nigeria comprises principals, vice principals and heads of department in secondary schools, and head teachers, assistant head teachers and heads of department in primary schools. According to a senior UNICEF official, interviewed by the researcher, the head teacher and head of department are responsible for instruction and guidance in the school, as well as providing leadership in classroom management, curriculum and content implementation and quality. The head teacher provides classroom observation and looks at the schemes of work passed to them by the heads of department.

The Zimbabwe Ministry of Education and Culture's (1993) conception of who is an instructional leader includes the school head, deputy head and heads of department. However, a study by Musandu (2018) shows that teachers perceive that school heads should focus on administrative and management duties while middle level managers, such as HoDs, who are subject specialists, should be the instructional leaders.

The collective evidence from these six countries is that the principal is usually regarded as the main instructional leader, although other professionals within the leadership structure may also contribute. The Zimbabwe data confirm international evidence that subject leaders are often preferred as instructional leaders by teachers. Elsewhere, it is perceived as a shared role, as noted globally by Hallinger (2019). Instructional leadership is likely to be more effective when it is widely distributed because this would involve more people in this crucial activity and would also enable different subject specialists to become involved.

\section{Balancing administrative and instructional activities}

Even where instructional leadership is explicitly advocated, there are tensions between the administrative and professional aspects of principals' roles. For example, in Malaysia, the Ministry of Education (2013) wants principals to focus on instructional, not administrative, leadership. However, research by Bush et al (2019) shows that principals continue to perform mainly as administrative leaders. This echoes research by Hallinger and Lee (2014) in Thailand.

Giving priority to administrative tasks is also evident in the six sub-Saharan countries. In Sudan, there is limited attention to the role of the principal as an instructional leader. In the regulations and policy documents, only three instructional leadership activities are mentioned, all of which relate to 
monitoring. These are lesson observation, checking teachers' lesson plans, and checking students' exercise books. Alkalifa and Adil (2015) found that school principals could not function as school leaders due to administrative and financial problems. Similarly, Ahmed (2014) note that principals spend $70 \%$ of their time on administrative activities instead of monitoring learning.

Nyambo's (2017) study of Tanzanian head teachers shows that their other work inhibited them from conducting instructional supervision. The author also notes that most heads did not have the opportunity to attend seminars about their role as internal instructional supervisors. The seminars that were provided focused on administrative issues (Nyambo, 2017). Similarly, Allieu (2019) reports that most head teachers in Sierra Leone are not aware of, and are not practicing, instructional leadership, including how to develop the school vision and mission statement.

Principals and head teachers in Nigerian schools are expected to be leaders, but how much they contribute to instructional leadership is unclear. Bello (2015) identifies the lack of a clearly defined instructional vision in schools, and ineffective instructional supervision by the headteachers. Student learning was not seen as a priority.

In Zambia, stakeholders interviewed by the researcher argue that heads are neglecting instructional leadership. For example, the principal education officer observes that 'head teachers have divorced themselves from classroom activities. They have directed most of their attention to running their offices and have neglected what happens in the classrooms'. The head teacher claims that most of the teaching and learning time is lost because of uncoordinated external meetings involving leaders and teachers. This robs schools of the desired contact time. Similar contradictions between administrative and instructional imperatives are evident in Zimbabwe. Makamani (2015) claims that school heads spend most of their time attending workshops and seminars called by their district offices and provincial offices. They experience work overload as they attend such meetings (Ncube 2013) and thus do not spend much time on instructional leadership issues (Manaseh (2016). This point illustrates policy inconsistencies. Heads are urged to become instructional leaders by senior policy makers while local officials demand their time for administrative activities, a situation also evident in Malaysia (Bush and Ng 2019).

The evidence from the six countries shows a fundamental dichotomy between the administrative and instructional roles of heads and principals. While instructional leadership is advocated in some contexts, for example in Zambia and Zimbabwe, official expectations are not clearly articulated and administrative demands are often more persuasive, especially when local officials call principals to external meetings. In other countries, notably in Sierra Leone and Sudan, there are few formal expectations that heads should be instructional leaders so most focus on their administrative roles. 
What is required is to reiterate that principals are head teachers, who mostly have professional backgrounds, and that instructional leadership should be their core role, and not a marginal adjunct to administration.

\section{Delegation and distributed leadership}

In many contexts, and in much of the literature, leadership and headship are aligned and the principal has the main responsibility for ensuring that the school provides an appropriate learning environment for students and staff. However, it is evident that, except in small schools, it is not possible for a single leader to take sole responsibility for school management. This has led to other senior and middle leader roles, such as deputy principals and heads of departments or subjects, being established in many education systems. However, little is known about how these leaders contribute to school organisation and management beyond a broad understanding that delegation or distributed leadership may be practiced (Bush 2020). Distributed leadership is the most popular model in the $21^{\text {st }}$ century but this is based mainly on research in decentralised systems with little evidence about how this works in hierarchical contexts (Bush and Ng 2019). Southworth (2004) claims that monitoring is a widely distributed role, including head teachers, deputies, and heads of department.

There is only limited evidence about distributed instructional leadership in the six sub-Saharan countries. Principals in Sudan are perceived to lack the basic skills for leading teaching and learning. The Africa Development Bank reports that senior and middle leaders all have certain instructional roles. Heads of department follow the academic progress and performance of the teachers, but their powers are limited to their departments. School principals spend most of their time on administration and finance.

The Zambian Ministry of Education (2019: 34) advocates that both collaborative and coaching approaches should be used for instructional leadership. Shipota (2020) comments that the policy demands that the school head must lead instruction but, inprcatice, they often detach themselves from the classroom and delegate this important role to their deputies and middle leaders. Nyambo, (2017) notes that some head teachers in Tanzania delegate their responsibilities to other leaders, especially deputy heads. However, the district education officer, interviewed by the researcher, claims that school leaders perceive that they are not responsible for classroom observation, or for giving feedback to teachers after observations, and checking lesson plans and schemes of work.

In Sierra Leone, Allieu (2019) reports that most head teachers are not aware of, and are not practicing, instructional leadership, and the author recommends that head teachers should delegate such 
responsibilities to other teachers. The SLTU senior official, interviewed by the researcher, also stresses that instructional leadership should be a distributed responsibility. 'You cannot expect only the principal or head teacher to be considered as an instructional leader ... the senior teachers and the teachers themselves [should] play an instructional leadership role'. There is no government training, but the British Council's CCGL team has introduced instructional leadership courses.

The Zimbabwean Ministry of Education and Culture's (1993) conception of who is an instructional leader includes the head, deputy head and heads of department (HODs), who are all expected to execute a combination of administrative and professional functions. This is an outdated source but Musandu (2018:132) notes that 'instructional leadership is considered by most of the teachers not as a solo effort, which is the prerogative of the school head only' but is best achieved through a democratised or broadened leadership. Chitamba (2019) adds that deputy heads and any designees appointed by the school head, and those in positions of responsibility, are regarded as instructional leaders. Teacher training courses do not include instructional leadership, so professionals are unprepared for this role.

In Nigerian schools, there is only a limited culture of delegation. However, Yahya (2015) claims that principals practice several leadership styles, including democratic and instructional leadership. In some schools, principals have the sole responsibility for developing curriculum and instruction for improving performance in the school and prefer not to delegate these responsibilities to other school staff. However, elsewhere, teachers and principals embrace delegation and engage in what may be called shared instructional leadership. The culture of delegation differs, as some principals may not fully embrace it (vice principal, Lagos). Imoni's (2020) study of distributed leadership in Edo State shows that it is largely indistinguishable from delegation.

The collective evidence from the six sub-Saharan African countries shows that the head or principal is regarded as the main instructional leader, with prime accountability for the quality of teaching and learning. However, heads have limited time to enact such responsibilities and, in practice, other senior and middle leaders, especially heads of department, may play a significant role, as in Tanzania and Zimbabwe. In other contexts, notably in Sierra Leone and Zambia, there is a normative orientation towards distributed instructional leadership, but with only limited evidence that this is being enacted. As noted earlier, instructional leadership is likely to be more effective if it is widely distributed.

\section{Resourcing Instructional Leadership}


The quality of school education is inevitably affected by the availability of an appropriate learning environment supported by adequate resources. This is a serious challenge in many sub-Saharan contexts (Bush and Oduro 2006).

In Sudan, none of the interviewed school principals had libraries or internet in their schools, and only two reported that they have computers in the school. The school principals mentioned several other problems, including lack of textbooks, drinking water, and teaching resources, as well as poorly maintained buildings and no provision to feed the children. There is limited data about resourcing the learning environment in Sierra Leone but one secondary school leader, interviewed by the researcher, stressed the importance of the school environment for instructional leadership:

The Zambia National Union of Teachers' (ZNUT 2017: 59) survey reveals several resource gaps, such as inadequate teaching and learning materials and equipment to cater for all learners. The survey also reveals that schools lack adequate computers or do not have any at all, creating another gap. The Ministry of Education (2019: 8) acknowledges that lack of access to teaching and learning materials and equipment present a 'fundamental' barrier to quality learning.

In Tanzania, there are disparities between levels of resource across communities and regions (UNICEF 2018): The correlation between inputs and outcomes in education in Tanzania is apparent, with regions with more resources performing above the average. Kaai's (2016) survey shows that most (75\%) teachers mentioned challenges such as lack of teaching and learning materials, and lack of infrastructure (classrooms, teachers' houses, latrines). A significant minority (25\%) noted problems such as lack of desks, overcrowded classrooms, lack of electricity and lack of first aid kits. The shortage of materials is also highlighted by Nyambo, (2017), who states that textbooks and other teaching materials were not in place for implementation of the new curriculum.

In Zimbabwe, there is a distinction between financial and material resources required to operate schools and those specific to instructional leadership. One stakeholder, interviewed by the researcher, commented that 'for budgets of small schools, the focus is on libraries and labs, while issues of pedagogy are something else'.

For Nigeria, Edna (2019) argues that contemporary methods are applied only in a limited way to teaching and learning. The Nigerian Policy on Education does not stipulate how resources such as time, money, materials, and expertise should be distributed, although it encourages hiring qualified teachers. Edna (2019) suggests that a way forward would be through organizing workshops for instructors on the use of innovative instructional methods, funding of teaching by government and 
NGOs, integration of technological media into curriculum content, and attitudinal changes of teachers towards innovation and in-service training.

Overall, the literature and data show significant challenges in respect of financial, human, and material resources in all six countries, consistent with previous research (e.g. Bush and Oduro 2006). The comment of the Zimbabwe stakeholder, that material resources are more important than pedagogical change, is likely to be echoed in the other five nations. However, this may be a false distinction in that working towards high quality teaching and learning should be a universal requirement, regardless of the funding available to resource the curriculum.

\section{Conclusion}

The literature reviews, and the stakeholder interviews, indicate developing awareness of the nature and significance of instructional leadership but with limited evidence of its enactment in these six subSahara African countries. Formal policy assumptions, where they exist, refer to the principal as the instructional leader, with only limited recognition that this needs to be a distributed responsibility if it is to be carried out at a sufficient scale to impact on classroom practice. Middle leaders need to be involved in instructional processes, because of their specific subject knowledge. In this conclusion, we first show how the research questions have been addressed and then consider the main broad themes arising from the research.

\section{Answering the research questions}

Who are regarded as school leaders and what do they do?

Globally, schools almost always have a senior leader with the title of principal or head teacher, usually supported by other leaders, such as deputy or vice-principal, and middle leaders, notably heads of departments or subject leaders. This near-universal model also applies in the six sub-Saharan countries. In all six countries, the head is regarded as the leader of the whole school, responsible for both administrative and educational activities.

In Sudan, the head is supported by one or two deputies and by department heads. The Zambian National policy identifies the school head as an instructional leader but there is little guidance on what this means. In Tanzania, head teachers are recognized as internal instructional supervisors, but Nyambo's (2017) study shows a lack of knowledge and skills about instructional leadership, illustrating a wider concern about the mismatch between formal expectations and instructional leadership practice. Similarly, principals in Sierra Leone are regarded as instructional leaders while, in Nigeria, the head teacher is responsible for instruction and guidance in the school, supported by heads of 
department. In Zimbabwe, the formal conception of an instructional leader includes the school head, deputy head and heads of department but some teachers believe that heads should focus more on administrative and management functions.

The evidence from these six countries is that the principal is usually regarded as the main instructional leader, although other professionals within the leadership structure may also contribute. Elsewhere, it is perceived as a shared role, as noted globally by Hallinger (2019).

\section{How do school leaders spend their time?}

The evidence from the six countries shows that there is a contradiction between formal expectations that principals should be instructional leaders and the practices reported in the literature and by the stakeholders interviewed by the researchers. The international literature also reports tensions between the administrative and professional aspects of principals' roles (Bush and $\mathrm{Ng}, 2019$, Hallinger and Lee 2014).

Giving priority to administrative, rather than instructional, leadership is evident in the six sub-Saharan countries. In Sudan, the literature shows that school principals could not function as school leaders due to administrative and financial problems. Similarly, in Tanzania, head teachers' other work inhibited them from conducting instruction supervision while heads in Sierra Leone were not aware of, and were not practicing, instructional leadership. Principals and head teachers in Nigerian schools are expected to be leaders but the literature (e.g. Bello 2015) identifies the lack of a clearly defined instructional vision in schools, and ineffective instructional supervision by the headteachers. In Zambia, stakeholders interviewed by the researcher argue that heads are neglecting instructional leadership and giving their attention to administrative issues. Similar challenges are evident in Zimbabwe, where heads spend much of their time attending workshops and seminars called by their district offices and provincial offices.

As noted earlier, there is a contradiction between the administrative and instructional roles of heads and principals. While instructional leadership is advocated in some contexts, for example in Zambia and Zimbabwe, official expectations are not clearly articulated, and administrative demands are often more persuasive. In other countries, notably in Sierra Leone and Sudan, there are few formal expectations that heads would be instructional leaders so most focus on their administrative roles. Student outcomes are unlikely to improve if heads, and their super-ordinates, privilege administration over their instructional roles.

What does the policy say about instructional leadership and who is responsible for it at school level? 
Policy statements indicate an orientation or an expectation that school leaders behave in specific ways. In three of these six sub-Saharan countries, Sudan, Zimbabwe, and Sierra Leone, there are no explicit policies related to instructional leadership, so it is unsurprising that that there is little evidence of it being enacted. In Zambia, Tanzania and Nigeria, expectations about principals as instructional leaders are included in policy statements but there are problems in its implementation. This may be due to weak understanding of the concept, as in Zambia, or because of the competing administrative demands, discussed above.

The collective evidence from these six countries indicates that there are either no explicit instructional leadership policies or that such policies are weakly articulated, with limited school-level awareness and enactment. None of these countries has a fully developed instructional leadership model, encapsulating advice about monitoring, modelling, and mentoring, as suggested by Bush (2013). Developing such a model would be a valuable starting point for effective instructional leadership.

What other leadership roles exist in schools that could possibly take on some of the administrative roles of school leaders?

In these six sub-Saharan countries, the leadership structures include senior and middle leader roles, such as deputy or vice-principal, and heads of departments, to support the principal. However, it is not always clear how administrative and instructional responsibilities are divided between and amongst these leaders.

In Sudan, the head teacher is supported by one or two deputies and by department heads. The deputy is expected to handle the smooth running of the daily activities of the school. Zambian school heads are profiled as instructional leaders, but little is known about whether other leaders, the deputy head teacher, and heads of departments are expected to be instructional and/or administrative leaders. There is little information about the role of Tanzanian senior and middle leaders as instructional or administrative leaders, but Nyambo (2017) notes that some head teachers delegate their responsibilities to other leaders, especially deputy heads.

In Sierra Leone, two stakeholders argue that senior teachers are considered to be instructional leaders as a result of their involvement in the development of teaching and learning in their schools, and because they may monitor whether the teachers are delivering their lesson plans. However, little is known about their role as administrative leaders. The Zimbabwe Ministry view is that deputy heads, and heads of department, as well as heads, are, or should be, instructional leaders. However, some 
teachers believe that heads have no instructional leadership role and should focus more on administrative and management functions.

Leadership structures in Nigeria comprise principals, vice principals, head teachers, assistant head teachers and heads of department. The principals oversee the day to day running of the school. The head teacher and heads of department are responsible for instruction and guidance in the school, as well as providing leadership in classroom management, curriculum and content implementation and quality. A school principal interviewed by the researcher claims that the principal, vice principal and heads of departments are all involved in instructional leadership.

The collective evidence from these six countries is that the principal is usually regarded as the main instructional and administrative leader, although other senior and middle leaders may also contribute to both instructional and administrative leadership. Distributing instructional leadership responsibilities is likely to enhance school and student outcomes.

What is the culture of delegation in schools?

There is a distinction between the management concept of delegation and the currently fashionable notion of distributed leadership. Delegation is linked to the hierarchy and occurs where a more senior leader, often the principal, allocates tasks to other staff, including teachers (Bush 2020). Accountability for the effective performance of such tasks is upwards through the hierarchy. Delegation for instructional tasks is usually to senior and middle leaders, such as deputy principals and heads of departments. Distributed leadership is presented as a different model, with leadership being emergent from anywhere in the organisation, independent of the formal leadership structure. However, this is based mainly on research in decentralised systems with little evidence about how this works in hierarchical contexts (Bush and Ng 2019). In practice, the language of distribution has been captured to describe practices that are often indistinguishable from delegation and may be regarded as allocative distribution (Bush 2020). Both delegation and distribution are used across the six countries.

In Sudan, the Africa Development Bank reports that senior and middle leaders all have certain instructional roles. Heads of department follow the academic progress and performance of the teachers, but their powers are limited to their departments. The deputy is expected to handle the daily activities of the school. Shipota (2013) comments that the policy in Zambia demands that the school head must lead instruction, but they often detach themselves from the classroom and delegate this important role to their deputies and middle leaders. Nyambo (2017) notes that some head teachers in Tanzania delegate their responsibilities to other leaders, especially deputy heads. 
In Sierra Leone, Allieu (2019) recommends that head teachers should delegate instructional responsibilities to other teachers, a view supported by a senior official, who argues that the role should be cascaded to a lower level. However, these are normative statements and may not represent school-based practice. The Zimbabwean Ministry expects the head, deputy head and heads of department to execute a combination of administrative and professional functions, including instructional leadership. Chitamba (2019) adds that deputy heads and any designees appointed by the school head, and those in positions of responsibility, are regarded as instructional leaders.

In Nigerian schools, there is only limited evidence of delegation. Yahya (2015) claims that principals practice several leadership styles, including democratic and instructional leadership. One viceprincipal argues that the culture of delegation differs across schools, as some principals may not fully embrace it.

The collective evidence from the six sub-Saharan African countries shows that the head or principal is regarded as the main instructional leader. However, heads have limited time to enact such responsibilities, so other senior and middle leaders may play a significant role, as in Tanzania and Zimbabwe. In Sierra Leone and Zambia, there is a normative orientation towards distributed leadership, but with only limited evidence that this is being enacted. Developing a system-wide culture of distributed instructional leadership would be a valuable step towards more effective classroom teaching.

\section{Thematic Overview}

The research findings from the six countries can be classified into three broad themes.

\section{Awareness of instructional leadership}

There is developing awareness about instructional leadership in these six countries, but it lacks a clear policy framework in some settings, for example in Zimbabwe. Even where policies refer to instructional leadership, as in Zambia, they are not supported by clear guidelines. In Tanzania, many heads are unaware of the concept. Awareness is an essential starting point for improved practice and requires specific training.

\section{$\underline{\text { Training for instructional leadership }}$}

Where there is a lack of awareness and understanding about instructional leadership, training is paramount. In Zambia, there is a lack of training or induction for instructional leadership, a problem replicated in Tanzania, Sierra Leone, and Zimbabwe. Similarly, professional development focused on instructional leadership is advocated in Nigeria. As noted in Sudan, principals can be more effective 
if they are well trained, empowered and equipped to be instructional leaders. The British Council's programme is one prominent example of training for instructional leadership.

\section{$\underline{\text { Research on instructional leadership }}$}

In several countries, including Tanzania, there is a perceived knowledge and capacity gap, and knowledge production remains modest. Further research is required to establish the extent and nature of instructional leadership and to assess which approaches are most effective in enhancing student learning.

These concluding comments support the international evidence that effective instructional leadership has the potential to make a significant positive impact on classroom practice, leading to enhanced student outcomes (Robinson, 2019), with benefits for children and young people, as well as helping countries to compete in an increasingly global economy. Despite this persuasive finding, the evidence from the six countries shows that heads and principals devote most of their time to administration and neglect instructional leadership. It is important to reiterate that principals are head teachers, who mostly have professional backgrounds, and that instructional leadership should be their core role, and not be subordinate to administration.

\section{Implications of the Study}

The findings from the synthesis of the 55 interviews, across six sub-Saharan countries, linked to a systematic review of the academic and official literature, lead to clear implications for policy and practice. At the system level, it is important for education ministries to articulate that the role of the school principal is primarily that of a professional leader, focused on developing teaching and learning through distributed instructional leadership. This is likely to require a new policy statement supported by clear guidance to school principals. At the school level, principals should introduce clear strategies for instructional leadership. The strategies required to enhance teaching and learning include monitoring, notably through classroom observation, with constructive feedback designed to encourage beneficial change rather than to damage teacher confidence. Developing and sustaining instructional leadership, at school and system level, is an important lever for beneficial change.

\section{References}

Ahmed, R. (2015), The Applications of School Principals of Administrative Skills in West Darfur Basic Schools. Available at: http://search.shamaa.org/FullRecord?ID=111767 (Accessed: 21 July 2020) Alkalifa, A. and Adil, M. (2015), Challenges facing School Principals working in University of Khartoum Affiliated Schools. Available at: https://jillrc.com/ (Accessed: 20 July 2020) 
Allieu. J. (2019), Training of head teachers' workshop in supportive supervision and instructional leadership, International Journal of Multidisciplinary Research and Publications, 1 (10): 1-12.

\section{Author (2020)}

Ayane, K.J. and Chekol, Y.G. (2019), Assessing the teaching-learning roles of instructional leadership in some selected primary schools, Journal of eSciences, 2: 1-10.

Bello, B. (2015), Towards revitalization of instructional leadership for effective implementation of universal basic education in Nigeria, Sokoto Educational Review, 16(1): 9.

Bush, T. (2013), Instructional leadership and leadership for learning: global and South African perspectives, Education as Change, 17 (S1): 5-20.

Bush, T. (2020), Theories of Educational Leadership and Management: Fifth Edition, London: Sage. Bush, T. and Oduro, G. (2006), New principals in Africa: Preparation, induction and practice', Journal of Educational Administration, 44 (4): 359-375.

Bush, T. and Glover, D. (2014), School leadership models: What do we know, School Leadership and Management, 34 (5): 553-571.

Bush, T. and Ng, A. (2019), Distributed leadership and the Malaysia Education Blueprint: From prescription to partial school-based enactment, Journal of Educational Administration, 57 (3): 279295.

Bush, T., Ng, A., Adul-Hamid, S. and Kaparou, M. (2018), School leadership theories and the Malaysia Education Blueprint: Findings from a Systematic Literature Review, International Journal of Educational Management, 32 (7): 1245-1265.

Bush, T., Ng, A.Y.M., Too, W.K., Glover, D. and Chay, J. (2019), Ensuring Acceptability and Feasibility: The Challenges of Educational Policy Reform, Singapore: The HEAD Foundation.

Chitamba, N. (2019), The role and experiences of deputy principals with instructional leadership in Zimbabwe, Doctoral dissertation, University of the Free State, South Africa.

Edna N.O. (2019), Application of contemporary instructional methods for curriculum delivery In Nigeria, Journal of Education and Social Sciences, 13 (1): 138-143.

Gumus, S. and Akcaoglu, M. (2013), Instructional leadership in Turkish primary schools: An analysis of teachers' perceptions and current policy, Educational Management, Administration and Leadership, 41 (3), 289-302.

Hallinger, P. (2003), Leading educational change: Reflections on the practice of instructional and transformational leadership, Cambridge Journal of Education, 33 (3): 329-350. 
Hallinger, P. (2019), Instructional leadership 1950-2018: Transformation from an American to a global leadership construct, in T. Bush, L. Bell and D. Middlewood, D. (Eds.), Principles of Educational Leadership and Management: Third edition, London, Sage.

Hallinger, P. and Heck, R. (1999), Can leadership enhance school effectiveness? In Bush, T., Bell, L., Bolam, R., Glatter, R. and Ribbins, P. (Eds.), Educational Management, Redefining Theory, Policy and Practice, London, Paul Chapman.

Hallinger, P. and Lee, M. (2014), Mapping instructional leadership in Thailand: Has education reform impacted principal practice, Educational Management, Administration and Leadership, 42 (1), 6-29. Imoni, R. (2020), A review of preparation and development of school leaders in Nigeria, in P. Moorosi and T. Bush (Eds.), Preparation and Development of School Leaders in Africa, London: Bloomsbury. Kaai P. (2016), Understanding and improving instructional leadership practices in primary schools in Karatu district, Arusha, Tanzania

Kabeta, R.M., Manchishi, P.C. and Akakandelwa, A (2013), Instructional leadership and Its effect on the teaching and learning process: The case of head teachers in selected basic schools in the central province of Zambia, International Journal of Science and Research, 6 (14): 876-1883.

Kaparou, M. and Bush, T. (2016), Instructional leadership in Greek and English outstanding schools', International Journal of Educational Management, 30 (6): 894-912.

Lambert, L. (2002), Leading as a form of learning: Implications for theory and practice, The Changing World of School Administration, NCPEA Yearbook.

Leithwood, K., Day, C., Sammons, P., Harris, A. and Hopkins, D. (2006), Seven strong claims about successful school leadership, London: DfES.

Makamani, M. (2015), An evaluation of the influence of instructional leadership on the performance of government and council schools in Harare province, MBA Thesis, University of Zimbabwe.

Manaseh, A. M. (2016), Instructional leadership: The role of heads of schools in managing the instructional programme, Mkwawawa University College of Education, United Republic of Tanzania. Ministry of Education (1996), Educating our Future; National Policy on Education, ZEPH: Lusaka. Ministry of Education, Malaysia (2013), Malaysia Education Blueprint 2013-2025, Putrajaya, MoE. Ministry of Education and Culture, Zimbabwe (1993), Handbook on School Administration for heads, Harare: Aloe Press.

Ministry of Education, Zambia (1996), Educating our Future, Lusaka: Ministry of Education. 
Ministry of Education and Culture, Zimbabwe (1993), Handbook on School Administration for heads, Harare: Aloe Press.

Ministry of Education and Vocational Training (2013), Government Policy, Dar Es Salaam.

Musandu, C. (2018), Zimbabwean teachers' perceptions and experiences of instructional leadership, Doctoral dissertation, University of the Free State.

Nyambo, L. (2017), The role of head teachers as internal instruction supervisors of pupils' academic performance in Tanzania, M.Ed. dissertation, The University of Dodoma, Tanzania

Office for Standards in Education (2003), Leadership and Management: What Inspection Tells Us? London, Ofsted.

O'Sullivan, M. (2006) Lesson observation and quality in primary education as contextual teaching and learning processes, International Journal of Educational Development, 26, 246-260.

Robinson, V. P. (2019), Excellence in educational leadership: Practices, capabilities and virtues that foster improved student outcomes, in T. Bush, L. Bell and D. Middlewood, D. (Eds.), Principles of Educational Leadership and Management: Third edition, London, Sage.

Robinson, V., Lloyd, C. and Rowe, K. (2008), The impact of leadership on student outcomes: The differential effects of leadership type, Educational Administration Quarterly, 44 (5): 635-674.

Shatzer, R., Caldarella, P., Hallam, P. and Brown, B. (2013), Comparing the effects of Instructional and transformational leadership on student achievement: Implications for practice, Educational Management, Administration and Leadership, 42 (4), 445-459.

Shipota, M. (2013), The Role of Teachers' Unions in the provision of workers' education in Kafue District, Zambia, Master's dissertation, University of Zambia.

Sibanda, J., Mutopa, S. and Maphosa, C. (2011), Teachers' perceptions of lesson observations by school heads in Zimbabwean Primary Schools, Journal of Social Sciences, 28 (1): 21-28.

Southworth, G. (2004), Learning-Centred Leadership, in Davies, B. (Ed.), The Essentials of School Leadership, London, Paul Chapman Publishing.

UNICEF (2018), Education Brief, UNICEF. (Tanzania)

UNICEF (2020). Fact Sheet, Available at: https://www.unicef.org/sudan/education (Accessed: 18 June 2020)

World Bank, (2014), Challenges of Poverty Reduction and Basic Service Delivery, Available at: https://openknowledge.worldbank.org/handle/10986/23506 (Accessed: 26 July 2020)

Yahya, S. A. (2015), Leadership styles, types and students' academic achievement in Nigeria. University Tun Hussein Onn Malaysia. doi:10.1145/3132847.3132886 
ZNUT (2017), Breadth of Learning: Measuring the breadth of learning in Zambian schools, Education International: Lusaka.

Blasé, J. and Blasé, J. (2004), Handbook of Instructional Leadership: How Successful Principals Promote Teaching and Learning, Thousand Oaks: CA, Corwin Press.

Bush, T. (2011) Theories of Educational Leadership and Management: Fourth Edition, London, Sage.

Bush, T. and Glover, D. (2003), School Leadership: Concepts and Evidence, Nottingham, National College for School Leadership.

Elmore, R. (2000), Building a New Structure for School Leadership, Washington, DC: Albert Shanker Institute.

Hallinger, P. (2003), Leading educational change: Reflections on the practice of instructional and transformational leadership, Cambridge Journal of Education, 33 (3): 329-350.

Hallinger, P. and Heck, R. (1999), Can leadership enhance school effectiveness? In Bush, T., Bell, L., Bolam, R., Glatter, R. and Ribbins, P. (Eds.), Educational Management, Redefining Theory, Policy and Practice, London, Paul Chapman.

Lambert, L. (2002), A framework for shared leadership, Educational Leadership, 59 (8): 37-40.

Leithwood, K., Day, C., Sammons, P., Harris, A. and Hopkins, D. (2006), Seven Strong claims about Successful School Leadership, London, Department for Education and Skills.

National College for School Leadership (2005), Annual Review of Research 2004-05, Nottingham, NCSL.

O'Sullivan, M. (2006) Lesson observation and quality in primary education as contextual teaching and learning processes, International Journal of Educational Development, 26, 246-260.

Robinson, V. (2007), School Leadership and Student Outcomes: Identifying What Works and Why? Melbourne, Australian Council of Leaders

Southworth, G. (2002), Instructional leadership in schools: reflections and empirical evidence, School Leadership and Management, 22 (1): 73-92.

Southworth, G. (2004), Learning-Centred Leadership, in Davies, B. (Ed.), The Essentials of School Leadership, London, Paul Chapman Publishing. 